Print ISSN: 2233-4165 / Online ISSN 2233-5382

doi:http://dx.doi.org/10.13106/jidb.2020.vol11.no2.49

\title{
A Study on the Opt-in Marketing
}

\author{
Won-Kyo OH*, Won-Jun LEE**
}

Received: December 31, 2019 Revised: January 30, 2020 Accepted: February 05, 2020

\begin{abstract}
Purpose: Online and social media and mobile shopping are increasing and companies are required to provide personal information in order to supplement the non-invasive characteristics of the channels. With the increased provision of personal information, consumers' personal and social concerns about the prevention of personal information infringement are also increasing, and in response, personal or opt-in marketing has emerged to compensate for reckless information abuse. Despite the background of this emergence, the existing prior studies are limited to ignoring the negative feelings of consumers in the real world, including only the net function and positive effect of the opt-in mail. Research design, data and methodology: The research framework was intended to utilize the impact of human marketing activities on consumer attitudes combined with positive and negative factors. Factors that positively affect attitudes toward permation marketing were presented, such as informality, and perceived risks were presented as negative impact factors. Also, based on previous prior research, the prior factors of opt-in marketing were to present the effect on purchase intent through the medium of attitude toward opt-in marketing. Results: In this study, we used the framework of a two factor theory to address positive and negative factors as a leading factor in the customer attitude toward opt-in mail advertising, and as a result, functionality and personalization have a positive effect on customer attitude and perceived risk have a negative impact on customer attitude. In addition, it was confirmed that the customer attitude formed this way affects the intention to purchase again. Conclusions: This study suggests that we have demonstrated that marketing, an opt-in marketing that has been recognized as part of marketing that is deployed after obtaining customer consent, has been applied without any other marketing methodology. E-mail advertising at this point also provides practical implications that the system safeguards are in place under an opt-in protocol or system, and that even if an e-mail advertisement is carried out, customers will need to look at the level of awareness about the risks, and suggests that they need to consider the customer's journey that could lead to purchase at the content level.
\end{abstract}

Keywords: Opt-in, Marketing, Customer Satisfaction, Perceived Danger, Permission Marketing

JEL Classification Code: M15, M31, M37

\section{Introduction}

온라인 쇼핑 및 다양한 소셜 미디어와 스마트폰 앱을 활용한 모바일 쇼핑 규모는 급격하게 증가하고 있다. 국내 온라인 쇼핑 시장규모는 2018 년을 기준으로 93.4 조 원 규모에 달하며 연평균 $19.4 \%$ 의 성장세를

*First Author. Department of Business Administration, Cheongju University, Korea, Email: owon21@naver.com

${ }^{* *}$ Corresponding Author. Professor, Department of Business Administration, Cheongju University, Korea, [Postal Address: Research Lab Bld. \#10-507, Cheongju University, Naeduk-dong, Cheongwon-gu, Cheongju, Chungbuk, 28503, Korea]

Email: marketing@cju.ac.kr

$\odot$ Copyright: Korean Distribution Science Association (KODISA)

This is an Open Access article distributed under the terms of the Creative Commons Attribution NonCommercial License (https://creativecommons.org/licenses/by-nc/4.0/) which permits unrestricted noncommercial use, distribution, and reproduction in any medium, provided the original work is properly cited.
보인다. 이 중 스마트폰 등 모바일 기기를 이용한 모바일 쇼핑의 이용률은 62.7\%에 달하고 있다(Personal Information Protection Commission, 2019). 이렇게 증대되고 있는 온라인 및 모바일을 비롯한 새로운 쇼핑 방식은 비대면 접촉을 전제로 진행되는 것이 특징이며, 이를 보완하기 위해 기업들은 본인 인증을 위한 개인정보 입력 및 배송지 주소, 전화번호, 이메일 등 연락처 등록, 공인인증서 등록, 결제용 신용카드 등록 등을 필수적 절차로 요구하고 있다. 개인정보 제공의 증대는 개인과 사회로 하여금 개인의 프라이버시 문제 및 개인정보 침해에 대한 우려를 낳고 있는데(Milne \& Rohm, 2000), 실제로 이와 관련하여 정보 위험은 심각한 수준에 이르고 있다. 정보 주체의 $77.0 \%$ 는 이미 개인정보 침해를 경험한 바 있으며(Personal 
Information Protection Commission, 2017), 개인정보의 유출과 오용 역시 심각한 수준에 이르는 것으로 알려져 있다. 기업들의 이런 적극적인 개인정보 수집 노력은 데이터베이스 마케팅 활용 증가에 귀인하고 있다. 고객의 사적인 정보는 무료상담 전화, 소매점 데이터 등으로 급격하게 외부로 유출되고 있으며, 기업들은 이런 정보를 적극적으로 마케팅 활동에 활용하고 있다(Milne \& Rhom, 2000).

최근 2020 년 1 월에는 국내 빅데이터 산업 발전을 목적으로 하는 '데이터 3 법(개인정보법, 신용정보법, 정보통신망법 개정안'이 국회 본회의를 통과하였다. 관련 업계에서는 데이터의 자율적인 활용이 가능해져 법안 통과를 환영하고 있는 반면, 관련 시민단체 및 전문가들은 '가명정보'의 추상성과 정보인권 보호에 대한 논의가 충분하지 않다는 의견 또한 나오고 있어 다시금 개인정보의 유익한 활용이 있어야 한다는 입장과 개인정보는 보호되어야만 한다는 상반되는 의견이 충돌되고 있다.

이러한 무분별한 정보 남용을 보완하기 위해 등장한 것이 퍼미션 마케팅(Permission marketing)이다. 퍼미션 마케팅은 일반적으로 고객의 동의를 사전에 얻고 마케팅을 전개하는 옵트인 마케팅(Opt-in marketing)으로 대변된다. 옵트인 마케팅은 인터넷을 매체로 활용함에 따라 매체 비용이 거의 소요되지 않고 실시간 정보제공이 가능하다는 점에서 일정 부분 고객 정보를 보호하며 효과적 마케팅을 펼칠 수 있는 대안으로 제시되어 빈번하게 사용되어 왔다. 그러나, 이러한 실무적 사용의 증가에도 불구하고 옵트인 마케팅에 관련된 기존 연구들은 기업의 입장을 대변하고 있으며 기업의 광고 수단으로서 옵트인 마케팅의 활용 방안이나 효과적인 제공방안 등 긍정적 입장만을 다루어왔다. 실제로 대만의 모바일 광고 인식조사에서 고객들이 옵트인을 한 모바일 광고일지라도 부정적인 태도가 발생할 수 있다는 결과가 도출되었고(Tsang, Ho, \& Liang, 2004), 개인정보침해를 경험한 소비자가 16 가지 이상의 부정적 감정을 지각한다는 연구 결과를 생각해볼 때, 부정적 영향을 배제한 연구 결과를 일반화하기에는 한계성이 존재한다.

이처럼 소비자 입장에서 옵트인 마케팅의 긍정적 영향과 부정적 영향을 균형 있게 다루는 연구는 매우 희소한 것이 사실이며, 이에 본 연구에서는 소비자들이 옵트인 마케팅을 통하여 지각하는 긍정 및 부정적 인식을 통합한 연구모델을 제시하고자 하며, 또한 기존 옵트인 마케팅에서 다뤄졌던 긍정적 요인이 현시점에도 고객태도와 구매의도에 미치는 영향이 유효한지를 검증하여 기업과 소비자 간 상생을 위한 발전 방향과 시사점을 제공하고자 한다.

\section{Literature Review}

\subsection{Increased Risk of Personal Information}

인터넷상의 개인정보 침해 사고는 구체적으로 개인정보의 무단 수집, 제 3 자에 대한 무단 제공, 타인 정보의 도용, 기타 합법적인 이용자 요구 불응 등 다양한 양상으로 펼쳐지고 있다. 이처럼 고객들의 개인정보가 기업의 원활한 업무처리를 위하여 고객의 동의 하에 수집되지만, 수집 시 공지된 이용 목적 이외의 용도로 활용되거나 사후 관리의 미흡으로 인한 정보 유출, 무단으로 제 3 자에게 제공되는 등 관련 사고는 빈번하게 발생하고 있으며, 개인정보 제공에 대하여 소비자가 느끼는 위험은 점증하고 있다.

소비자가 지각하는 위험성은 불확실성에서 비롯되며, 소비자가 어떤 행동 또는 행위를 하거나 주변 환경의 변화가 발생할 때 지각된다. 지각된 위험은 성과, 재무, 시간, 사회, 그리고 프라이버시 위험이 존재하며, 특히 개인정보 보호가 적절하게 제공되지 않았을 경우, 다른 위험들보다 프라이버시 침해에 대한 위험이 높게 지각된다. 프라이버시는 혼자 있을 권리나 타인의 부당한 침해로부터 자유로울 수 있는 권리이며(Warren \& Bradies, 1980), 최근에는 그 적용 범위를 온라인까지 확대하여 개인정보 전반에 대한 보호 범위를 지칭하는 의미로 사용되고 있다. 최근 인터넷을 통한 회원 가입, 거래 증가 등과 연계되어서, 개인이 제공해야 할 정보의 양이 증대하면서 프라이버시 보호의 중요성이 증대하고 있다. 이러한 위험성에 대한 지각이 심화할수록 소비자들은 불안감에 사로잡히며 온라인상에서의 구매를 주저하게 된다(Hoffman, Novak, \& Peralta, 1999). Malhotra, Kim and Agarwal(2004)에 따르면 프라이버시 위험에 대한 지각 증대는 전자상거래의 성장 저해요인 중 하나로 꼽힌다. 이를 해결하기 위해 지난 100 여 년간의 학술적 연구를 통한 프라이버시에 대한 정책적, 기술적 진보에도 불구하고 프라이버시 침해에 대한 우려는 감소하지 않고 있으며 오히려 더욱 증대되고 있다고 할 수 있다(Westin, 2003). IT 기술의 발달로 인해 수많은 문명적 혜택을 누리게 되며 정보화 사회에서는 개인정보를 지식정보로써 활용성을 제고해야 한다는 측면(Noberg \& Horne, 2007)과 개인의 사적인 지식재산권이 침해되는 것이라는 측면(Daivs, 1997)이 대치하는 역설적인 상황이 작용하여 문제점들이 해소되지 않고 있는 상황이라 할 수 있다. 결론적으로 개인정보에 대한 위험성 지각은 개인정보 제공 동의를 기반으로 마케팅을 전개하는 옵트인 마케팅에서는 필수적으로 고려되어야 하는 요인이라고 할 수 있다.

\subsection{Permission Marketing}

프라이버시 위험이 커질수록 소비자들은 개인정보가 안전하게 보호되고 적절하게 사용될 것이라는 확신이 어려우며, 기업에 개인정보를 제공하거나 관련된 마케팅 활동에의 참여 역시 위축될 것이다. 이에 따라 고객으로부터 사전동의를 얻는 절차의 중요성이 강조되기 시작하였다. 고객에게 개인 데이터 사용 가능 여부를 사전에 
확인하고, 개인정보의 수집과 프라이버시를 지킬 권리를 고지하는 것은 기업이 추구해야하는 개인정보 보호의 핵심이다Foxman \& Kilcoyne, 1993).

이와 관련하여 퍼미션 마케팅의 개념이 주목받기 시작하였다. 상호작용이 빈번하고, 고객 정보의 수집과 활용 비용이 저렴한 인터넷의 등장은 퍼미션 마케팅 시대를 열게 되었다(Godin, 2000). 기존의 기업들이 수행하던 무작위 마케팅인 스팸메일이나 스팸문자는 소비자들로부터 사전동의를 받지 않음에 따라 사생활 침해 가능성이 높았으며, 소비자들은 해당 마케팅 활동에 무반응 혹은 무시나 적극적 거부를 표시함으로써 마케팅 노력이 저하되어 왔다. 퍼미션 마케팅은 이런 기존 마케팅 활동의 단점을 극복하고 차별성을 확보할 수 있는 대안으로 제시되어 왔다(Sul, 2000). 퍼미션 마케팅은 소비자의 동의 여부가 기업 이익 창출에 직접적인 영향을 미친다는 신념 하에, 소비자의 자발적 참여를 통하여 자사 서비스에 대한 소비자의 친숙성을 높이고 장기적으로는 충성고객을 확보하기 위한 마케팅이다. 온라인상의 마케팅 활동과 관련하여 퍼미션 마케팅의 많이 논의되고 있으나, 사실상 온라인뿐만 아니라 오프라인 환경하에서도 유효한 수단이며, 고객의 동의를 얻고 기업 마케팅 활동의 선택권을 고객에게 부여하는 모든 마케팅 활동을 의미한다. 따라서 성공적인 퍼미션 마케팅은 고객들에게 얼마나 이해, 허가, 지지를 얻어낼 수 있는가에 달려 있다. 인터넷 마케팅상의 퍼미션 마케팅은 옵트인과 옵트아웃 이메일을 중심으로 전개된다(Bellman, Johnson, \& Lohse, 2001). 옵트인 마케팅은 수신자의 동의를 획득하기 이전에는 메일 발송이 금지되는 장치이며, 반면에 옵트아웃은 수신자의 동의 없는 메일 발송이 가능하지만, 소비자가 수신거부 의사표시가 이루어진 다음부터는 발송이 금지되는 장치이다. 특히 옵트인 광고는 CRM 및 1:1 마케팅에 앞서 사전에 동의를 구한다는 점에서 퍼미션 마케팅의 개념에 가장 부합하는 형태로 인식되고 있다(Tezinde \& Hise, 2000).

\subsection{Opt-in Marketing}

퍼미션 마케팅에 가장 부합하는 형태로 고객의 동의를 받고 광고나 홍보물을 이메일로 발송하는 옵트인 마케팅은 메일을 받는 수신자에게 정보를 검색하는 노력을 줄여주기 위해 고객이 원하는 정보를 선별해줄 수 있다. 또한 수신자가 해지를 하고 싶다면 언제든지 해지를 신청할 수 있도록 함으로써 정보를 거부할 수 있는 권리를 부여한다. 발신자 입장에서 옵트인 마케팅은 수신자의 선별 즉, 타겟팅이 용이하다는 특성을 갖는다. 고객에게 수신 동의를 받음과 동시에 고객이 원하는 정보의 유형을 선택할 수 있도록 하는 등의 활동이 수반되기 때문에 기업은 제공가능한 정보의 유형별로 수신자를 선별하여 배포할 수 있다. 최근에는 듀얼 옵트인 마케팅(Dual Opt-In marketing)으로도 전개되는 양상을 보이고 있고, 듀얼 옵트인 마케팅은 최초
웹페이지에서 메일 수신 동의를 획득한 후, 추후 발송되는 메일에서 다시 동의 여부를 선택할 수 있도록 하는 방식으로 의도치 않은 기업 메일의 스팸화를 방지할 수 있도록 한다.

선행연구에 따르면, 소비자의 정보 유출 및 사생활 침해, 무반응 등에 대한 기업의 노력은 긍정적 영향을 가질 수 있음을 알 수 있는데, Ramkumar(2007)는 옵트인 메일과 기업 이미지 간의 관계 분석을 통하여 옵트인 메일의 주요한 특성들은 기업 이미지에 긍정적 영향을 미침을 발견하였다. 이들이 주장한 옵트인 메일의 특성에는 기능성과 정보성, 정서성이 존재한다. 또한, 옵트인 메일이 아니더라도 전통적인 소비자 행동 모델에 있어서도 Ducoffe(1996)의 웹 광고 효과 모델에 따르면 광고 태도를 결정짓는 선행요인에는 광고의 정보성 및 오락성, 성가심, 가치 등이 중요한 요인으로 등장한다. 그러나 Ramkumar(2007)의 연구는 옵트인 메일의 순기능만을 모형에 포함하였다는 점에서 설명력의 한계가 있으며, 관련 연구로 기존의 연구에서 정보성, 기능성, 정서성, 그리고 개인화의 긍정적 효과들이 주장되었다(Smith \& Swinyard, 1982). 이러한 연구는 현실 속 소비자들의 부정적 감정을 무시하였다는 한계가 있다. 또한, 옵트인 메일과 같은 단기적 수단이 매개효과 없이 이미지와 같은 장기적 브랜드 자산에 직접 영향을 준다는 연구모형은 소비자 태도와 같은 매개 변수의 필요성을 제기한다.

\section{Hypothesis}

\subsection{Research Framework}

본 연구는 Herzberg, Mausner and Snyderman(1959)이 주장한 2 요인 이론의 적용을 통해 기업의 옵트인 마케팅의 긍정적 요인과 부정적 요인을 통합하여 연구를 진행하고자 한다. Herzberg et al.(1959)의 2 요인 이론은 직무 만족도를 설명하는 것을 넘어서 소비자 만족 등 마케팅 상황에도 유용한 것으로 알려져 왔다(Praff, 1973). 마케팅 연구에서는 이를 변형하여 만족, 불만족에 미치는 요인들이 중복되지 않으며, 각각 개별적으로 존재함을 주장하였다. Swan and Comb(1976)는 소비자의 만족도는 표현적 차원과 도구적 차원이 영향을 미치며, 표현적 차원은 구매하는 소비자의 목적으로도 동기 요인에 해당하며, 도구적 차원은 목적 달성에 필요한 수단적 역할을 하는 요인으로서 위생 요인에 해당한다고 주장하였다.

이러한 선행 연구를 바탕으로, 퍼미션 마케팅 활동이 소비자 태도에 미치는 영향은 긍정적 요인과 부정적 요인이 병립한다는 연구 프레임워크를 활용하고자 한다. 퍼미션 마케팅에 대한 태도에 긍정적 영향을 미치는 요인으로는 기존 이메일 연구에서 순기능으로 반복적으로 제시되었던 정보성, 기능성, 정서성, 개인화를 제시하였고, 
부정적 영향요인으로서는 개인정보의 공유와 활용에 따라 가장 빈번하게 문제가 제기되었고, 개인의 위험 지각도 큰 프라이버시 위험을 제시하였다. 또한, 기존의 선행 연구를 바탕으로, 퍼미션마케팅에 대한 태도를 매개로 고객 구매의도에 미치는 영향을 제시하고자 한다.

\subsection{Hypothesis Setting}

정보성의 효과에 관한 연구로서, Dufrene, Engelland and Pearson(2005)은 이메일을 이용한 상업적 광고의 특성을 분석한 후, 정보획득 가능성, 오락성이 기업 이미지 형성에 긍정적 영향을 미친다고 주장하였다. 또한 $\operatorname{Gorla(2012)ㄴㅡㄴ~ㄱㅘㅇㄱㅗㄹㅡㄹ~ㅌㅗㅇㅎㅐㅅㅓ~ㅇㅠㅇㅛㅇㅎㅏㄴ~}$ 정보를 획득할 수 있다면, 고객 충성도를 강화할 수 있다고 주장하였다. 이러한 양상은 최근 부각되고 있는 SNS 인 인스타그램에서의 화장품 판매에 있어 정보성과 유용성 그리고 소비자태도 및 구매의도 간의 관계를 연구한 Davis(1989)의 연구에서도 마찬가지로 정보성은 소비자 태도에 직접적인 영향을 미치는 것으로 나타났다. 이는 단연 인스타그램뿐만 아니라 블로그와 트위터, 페이스북에서도 SNS 유형별 광고속성 중 정보성은 소비자들의 광고태도에 긍정적인 영향을 미치는 것으로 나타났다(Duffett, 2015). 비대면적 마케팅 채널에 있어서는 이처럼 소비자들의 태도에 정보성이 긍정적인 영향을 미친다는 연구가 다수 존재하며, 이는 기존 4 대 매체뿐만 아니라 SNS 채널에서도 동일한 효과성이 입증되었다. 이에 따라 옵트인 마케팅의 정보성은 고객태도에 긍정적인 영향을 미치리라는 것을 예상해볼 수 있다.

H1: 정보성은 고객태도에 긍정적 영향을 미칠 것이다.

제품의 기능성을 비롯한 여러 제품 속성이 구매의도에 미치는 상대적 영향력에 대한 연구는 많이 있었다(Chitturi, Raghunathan, \& Mahajan, 2007). 특히 온라인 쇼핑몰과 관련해서는 서비스 품질의 결정요인이 기능성디자인 품질 및 즐거움, 신용, 과정 등 인터넷 환경에 맞게 재구성된 바가 있으며(Bauer, Falk, \& Hammerschmidt, 2005), 이들 요인은 전자상거래 성과에 긍정적인 영향을 미치는 것으로 나타났다. 또한 쇼핑몰 사이트의 기능성과 디자인은 고객만족도에도 유의한 영향을 미치는 것으로 나타났는데(Szymanski \& Hise, 2000), 해외 연구와 마찬가지의 결론으로 $\mathrm{Ahmad}$ and $\mathrm{Al}-\mathrm{Zu}$ 'bi(2011)가 진행한 e-만족 선행요인에 관한 연구에서도 기능성이 e-만족에 긍정적 영향을 미치는 것으로 나타났다. 홈페이지 광고 분야에서의 연구를 살펴보면, 인터넷 쇼핑몰에서의 만족도는 쇼핑몰의 디자인 요소와 마케팅 기능이 고객만족에 긍정적인 영향을 미치는 것으로 밝혀졌고(Bai, Law, \& Wen, 2008), 홈페이지 광고 메시지 전략에 관한 연구에서
Lee(1997)은 행사 안내와 같은 기능적 요인을 메시지 전략을 구성할 시 고려해야 하는 긍정적인 요인으로 꼽았다. 본 연구와 유사한 분야인 이메일 광고의 효율성 강화를 위한 연구에서 효율적 이메일 광고의 특성은 기능적 특성과 유사한 유용성이 제시되었으며(Palmer \& Griffith, 1998), 기능성과 더불어 정보성, 신뢰성, 흥미성, 성가심, 개인화가 이메일 광고의 효율성을 증진할 수 있는 요인으로 도출되었다 이러한 점으로 미루어 볼 때 온라인을 기반으로 하는 마케팅에는 홈페이지 활용, 해당 웹사이트에 게시되는 메시지, 이에 대한 광고를 전달하기 위한 도구 등을 막론하고 기능성이 고객태도에 긍정적인 영향을 미칠 수 있는 요인으로 설명되고 있음을 알 수 있으며, 이에 따라 본 연구에서도 기능성이 고객태도에 긍정적인 영향을 미치리라는 것을 기대할 수 있을 것이다.

H2: 기능성은 고객태도에 긍정적 영향을 미칠 것이다.

정서성의 영향에 관하여는 서비스 마케팅에서 폭넓게 지지가 되어온 서브퀄(SERVQUAL) 모형을 기반으로 한 선행연구를 통해 확인할 수 있다. 선행 연구들에서는 온라인 쇼핑에서 지각되는 품질 차원의 일부로 공감성이 고객 만족에 미치는 영향을 주장하였는데(Gefen, 2002), 이는 정서성의 태도에 대한 긍정적인 효과를 예측하게 한다. 온라인 광고에 한하여 MacKenzie, Lutz and Belch(1986)은 온라인광고의 정서성은 온라인 광고의 지속 가능한 발전 요인 중 하나이며, 광고태도에 긍정적인 영향을 미친다고 하였고, 이와 다른 측면인 오프라인에서도 패밀리레스토랑에서의 소비경험 연구를 진행한 Agarwal and Karahanna(2000)의 연구에 따르면 소비자의 소비경험 중 정서성이 고객만족에 영향을 미친다고 하였다. 긍정적 고객태도의 형성이 고객만족을 불러일으킨다는 점에서 정서성은 고객태도에 긍정적인 영향을 미친다는 것을 예측할 수 있다. 이를 공익캠페인에 적용하여 캠페인 수용자들의 태도를 살펴본 Lewis, Watson and White(2010)의 금연연구에서도 캠페인의 정서성이 광고를 통한 설득의 차이를 일으킨다는 것을 확인하였다.

H3: 정서성은 고객태도에 긍정적 영향을 미칠 것이다.

개인화 광고의 대표적인 사례로 온라인 맞춤형 광고는 수용자의 광고 회피를 최소화하고 효과성을 제고하기 위해 고안된 새로운 방식의 온라인 광고이며, 이는 웹사이트에 존재하는 온라인 이용자의 정보를 수집하고 이를 분석하여 개인화된 광고내용을 제공하는 것을 의미한다 (Li \& Huang, 2016). 광고를 제공하는 방식에 있어서 소비자들은 일반적인 광고보다는 개인화된 광고를 더 유용하다고 여기기 때문에 맞춤형 광고에 더욱 집중하게 된다(Ur, Leon, Cranor, Shay, \& wang, 2012). 이러한 개인화와 소비자 반응에 대한 실증연구에는 서비스에 대한 개인화 수준이 높아질수록 해당 서비스에 대한 
수용의도가 높아진다(Campbell \& Wright, 2008)는 연구와 웹 기반 추천 시스템에 대한 연구에서도 시스템의 개인화는 설득 메시지 수용자의 긍정적 의도를 향상시키는 것으로 나타났다는 연구(Komiak $\&$ Benbasat, 2006) 등 다양한 연구들이 존재한다. 반대로 광고회피에 있어서 온라인 맞춤형 광고는 부정적인 효과를 나타내는 것으로 나타났으며(Li \& Huang, 2016), 이러한 주장들에 따르면 광고의 개인화는 소비자의 태도 형성에 긍정적인 영향을 미친다는 것을 짐작할 수 있을 것이다.

H4: 개인화는 고객태도에 긍정적 영향을 미칠 것이다.

기업이 소비자로부터 필요한 개인정보를 획득할 수 있는가는 이런 행위로부터 지각되는 위험의 수준과 관련이 있다. 프라이버시에 관한 선행 연구들은 고객만족과 같은 태도들이 과거의 개인정보 제공이 성공적인 경험이었는지에 대한 판단에 따라 달라진다고 주장한다(Milne \& Rohm 2000). 더 많은 개인정보 통제권을 소비자에게 돌려주고, 그 효과로 지각된 위험이 줄어든 경우에는 기업과 소비자 간의 분쟁의 여지가 줄어들며, 고객의 태도도 더 긍정적으로 바뀐다(Foxman \& Kilcoyne 1993). 이러한 지각된 위험과 고객태도 간에 관한 연구는 제품과 서비스 그리고 이들의 유형에 따라서도 다각적으로 연구되어 왔는데, 식품과 같은 비 전자제품에 대한 태도와 첨단 디지털 디바이스와 같은 전자제품에 대해서도 모두 지각된 위험은 고객태도에 부정적인 영향을 미치는 것으로 나타났고(Bredahl, 2001; Peter \& Ryan, 1976), 서비스에 있어서도 기존 인터넷뿐만 아니라 이를 기반으로 한 SNS 및 소셜커머스 서비스에서도 지각된 위험은 동일한 영향력을 보인다(Jacoby \& Kaplan, 1972). 이처럼 제품과 서비스 그 어느 분야를 막론하고 지각된 위험은 그 정도의 차이만 있을 뿐 고객태도에 부정적인 영향을 미친다는 연구가 지속적으로 있었다. 옵트인 마케팅 또한 기업의 제품 및 서비스를 제공하면서 전개되는 마케팅 프로그램의 일환으로 옵트인 메일로 인해 지각되는 위험성은 기존 연구들과 마찬가지로 고객태도에 부정적인 영향을 미칠 것으로 판단할 수 있다.

H5: 지각된 위험은 고객태도에 부정적 영향을 미칠 것이다.

태도는 행동의 선행 요인이며, 퍼미션 마케팅에서도 예외는 아니다. 다수의 연구에서 기업에 대한 긍정적 이미지나 태도 형성, 만족도는 관계 지속의도, 구매 의도 등 의도 그리고 충성도에 긍정적 영향을 미침을 주장하였다(Kim \& Park, 2019). 결과적으로 태도가 행동의도를 촉발하는 선행요인이라는 것은 합리적 행위이론이 적용된 다양한 연구에서 긴 세월 동안 다양한 형태로 실증되어 왔고, 수용되어 왔다는 것을 알 수 있다. 실례로 선행연구에 따르면 광고의 속성이 광고태도를 매개로 구매의도에 긍정적인 영향을 미치며, 광고태도와
구매의도 간 직접적인 영향 이외에도 브랜드 태도를 매개로 하는 간접효과 또한 존재한다는 것이 밝혀졌다(Brown \& Stayman, 1992; Holbrook \& Batra, 1987; Mitchell \& Olson, 1981; Stayman \& Aaker, 1988). 또한 기존 웹 광고 이외 SNS 의 특성 또한 소비자태도를 매개로 구매의도 및 온라인 구전에 영향을 미치는 것으로 나타났으며(Kim, Choi, \& Shin, 2019), 오프라인 마케팅에서도 고객의 점포에 대한 태도 또한 구매의도 및 브랜드 자산에 긍정적인 영향을 미치는 것으로 밝혀졌다(Fan, Kim, \& Cui, 2010). 단순 제품에서도 이는 별반 다르지 않은데, 제품에 각인된 친환경 인증마크는 제품태도를 매개로 구매의도에 긍정적인 영향을 미친다는 것을 실증한 연구(Bahn \& Wright, 2001)와 기업에 대한 고객의 태도를 다룬 연구에서도 고객태도는 고객만족과 애호도를 매개로 구매의도에 긍정적인 영향을 가지며(Chaudhuri \& Holbrook, 2001), 기업에 대한 태도와 지각도 및 유능함은 제품에 대한 구매의도를 증가시키는 것으로 분석되었다 $(\mathrm{Kim} \&$ Park, 2019). 이처럼 대상을 막론하고 고객의 태도는 구매의도에 긍정적인 영향을 미칠 것이라는 선행연구는 상당수 존재하며, 본 연구에서도 마찬가지로 동일한 효과를 얻을 수 있을 것으로 판단해볼 수 있다.

H6: 고객태도는 구매의도에 긍정적 영향을 미칠 것이다.

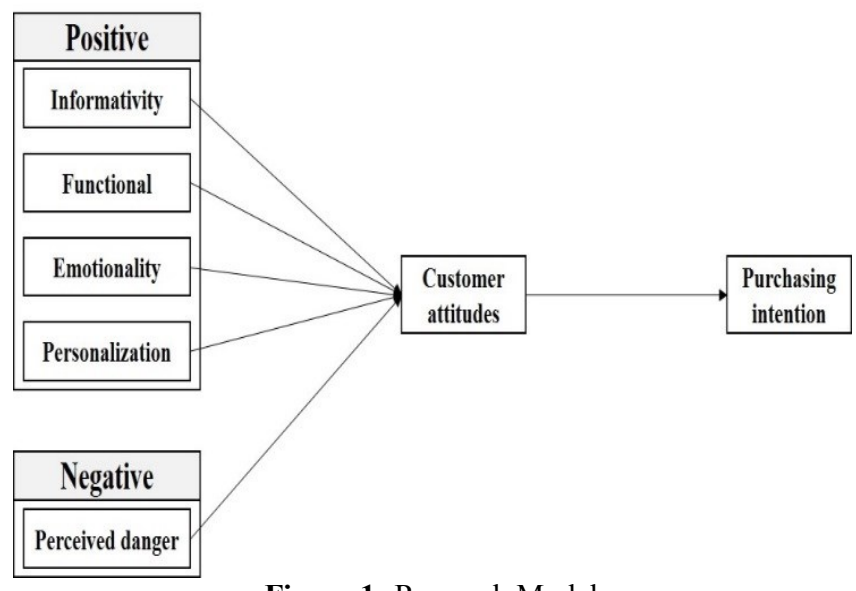

Figure 1: Research Model

\section{Research Procedure}

\subsection{Sample Selection}

본 연구를 위한 표본은 약 1 주일간에 걸쳐 전문 마케팅리서치 기관을 통하여 데이터 수집이 이루어졌다. 대상 지역은 대전, 청주를 포함한 충청남북도 지역을 중심으로 설문 조사가 이루어졌으며, 회수된 
320 부의 설문지 중 결측치가 과다하거나 불성실 응답으로 추정되는 10 부를 제외한 후, 총 310 부를 분석에 사용하였다.

Table 1: Fundamental Response Characteristics

\begin{tabular}{|c|c|c|c|}
\hline \multicolumn{2}{|c|}{ Characteristics } & Frequency & Percentage(\%) \\
\hline \multirow{3}{*}{ Gender } & Male & 82 & 26.5 \\
\cline { 2 - 4 } & Female & 228 & 73.5 \\
\hline \multirow{4}{*}{ Age } & Under 20 & 9 & 2.9 \\
\cline { 2 - 4 } & $20 \sim 29$ & 58 & 18.7 \\
\cline { 2 - 4 } & $30 \sim 39$ & 84 & 27.1 \\
\cline { 2 - 4 } & $40 \sim 49$ & 117 & 37.7 \\
\cline { 2 - 4 } & Over 50 & 42 & 13.5 \\
\hline \multirow{7}{*}{ Occupation } & Student & 35 & 11.3 \\
\cline { 2 - 4 } & Self-employed & 31 & 10.0 \\
\cline { 2 - 4 } & Emplyee & 77 & 24.8 \\
\cline { 2 - 4 } & Official & 21 & 6.8 \\
\cline { 2 - 4 } & Housewife & 123 & 39.7 \\
\cline { 2 - 4 } & Other & 23 & 7.4 \\
\hline
\end{tabular}

응답자의 기초통계자료를 분석하면 성별 특성으로는 남성 $26.5 \%$, 여성 $73.5 \%$ 로서 여성의 비율이 다소 높았다. 연령대별 특성으로는 20 세 미만(2.9\%), 30 세 미만(18.7\%), 40 세 미만(27.1\%), 50 세 미만(37.7\%), 50 세 이상 $(13.5 \%)$ 으로 나타났다. 직업별로는 주부 $39.7 \%)$ 의 비중이 상대적으로 높았으며, 회사원(24.8\%), 학생 $(11.3 \%)$, 자영업자 $(10.0 \%)$, 공무원 $(6.8 \%)$, 기타(7.4\%)로 나타났다.

\subsection{Variable Definition and Sacale}

본 연구모형에 투입된 변수들은 정보성, 기능성, 정서성, 개인화, 지각된 위험, 고객 태도, 구매 의도이며 기존 선행연구를 바탕으로 연구 상황에 적합하도록 자구 수정을 거친 후, 등간 척도인 리커트(Liket) 5 점 척도의 다항목 변수들로 측정되었다.

우선 각 변수에 대한 조작적 정의를 살펴보면, 정보성은 소비자가 옵트인 메일을 수신 동의함에 따라 유무형의 인센티브 등 보상, 정보나 지식을 얻을 것으로 예상하는 정도로 정의된다(Sinkovics, Pezderka, \& Haghirian, 2012). 기능성은 소비자가 옵트인 메일을 수신 동의함에 따라 시간 및 공간적 비용을 절감하고 편리성을 높일 것이라고 예상하는 정도로 정의하였다(Sinkovics et al., 2012). 정서성은 소비자가 옵트인 메일을 수신 동의함에 따라 긍정적인 기분이나 감정의 변화를 얻을 것으로 예상하는 정도(Dwyer, Schurr $\& \mathrm{Oh}, 1987)$ 이다. 개인화는 소비자가 옵트인 메일을 수신 동의함에 따라 자신에게 적합하거나 자신만을 위한다는 느낌을 제공하는
정도(Sinkovics et al., 2012)로 정의된다. 지각된 위험은 소비자가 옵트인 메일을 수신 동의함에 따라 자신의 의지와 무관하게 제공한 개인정보 유출 등 사생활 침해를 당할 수 있다고 우려하는 정도로 정의된다(Smith, Milberg, \& Burke, 1996). 고객 태도는 옵트인 메일의 수신자가 해당 발신자의 제품이나 서비스에 대하여 느끼는 긍정적 정서나 감정을 의미하며(Bai, Law, \& Wen, 2008), 구매 의도는 옵트인 메일의 수신자가 해당 발신자의 제품이나 서비스를 구매하려는 의도이다 (Jarvenpaa \& Todd, 1997).

\subsection{Reliability and Validity Analysis}

Table 2: Correlation Analysis Results

\begin{tabular}{|c|c|c|c|c|c|c|c|}
\hline Variables & 1 & 2 & 3 & 4 & 5 & 6 & 7 \\
\hline 1. Informativity & 1 & & & & & & \\
\hline 2. Functional & $.568^{* *}$ & 1 & & & & & \\
\hline 3. Emotionality & $.488^{* *}$ & $.472^{* *}$ & 1 & & & & \\
\hline 4.Personalization & $.472^{* *}$ & $.422^{* *}$ & $.735^{* *}$ & 1 & & & \\
\hline $\begin{array}{l}\text { 5.Perceived } \\
\text { danger }\end{array}$ & .130 & .098 & -.010 & -.085 & 1 & & \\
\hline $\begin{array}{c}\text { 6.Customer } \\
\text { attitudes }\end{array}$ & $.258^{* *}$ & $.312^{* *}$ & $.339^{* *}$ & $.376^{* *}$ & $-.309^{* *}$ & 1 & \\
\hline $\begin{array}{l}\text { 7.Purchasing } \\
\text { intention }\end{array}$ & $.472^{* *}$ & $.425^{* *}$ & $.366^{* *}$ & $.348^{* *}$ & -.052 & $.480^{* *}$ & 1 \\
\hline
\end{tabular}

신뢰성 측정을 위하여 가장 보편적으로 사용되는 Cronbach's alpha 계수를 측정하였다. 측정 결과 정보성( $(0.910)$, 기능성( $(0.902)$, 정서성 $(0.933)$, 개인화 $(0.935)$, 지각된 위험( $(0.922)$, 고객태도( 0.847$)$, 구매의도(0.833) 수준으로 나타나, EG Carmines and RA Zeller(1979) 등의 연구에서 제시되고 있는 보편적 판단 기준인 0.7 수준을 모두 상회하는 것으로 나타났다.

타당성 분석을 위해서는 연구에 사용된 모든 측정항목을 투입한 후, 요인 분석을 하였다. 배리맥스 회전과 주성분 분석을 적용하여 분석한 결과, 기능성, 정서성, 개인화, 지각된 위험, 고객태도, 구매의도의 총 7 개의 요인이 예상한 바대로 유의하게 도출되었으며, 이들 요인의 총 아이겐 값은 28.809 , 총 설명 분산은 $70.267 \%$ 의 양호한 수준으로 판단되었다. 표본 적합도 평가와 구형성 검정은 $\mathrm{KMO}$ 와 Bartlett 의 구형성 검정을 통해 확인하였는데, 우선 $\mathrm{KMO}$ (Kaiser-MeyerOlkin) 측도는 0.920, Bartlett's $x^{2}$ 은 9,380.385(p<000)로 나타나 KMO 측도 기준에 적합한 수준인 것으로 확인되었다. 
Table 3: Factor Analysis Results

\begin{tabular}{|c|c|c|c|c|c|c|c|c|}
\hline \multicolumn{2}{|l|}{ Factors } & 1 & 2 & 3 & 4 & 5 & 6 & 7 \\
\hline \multirow{8}{*}{ Perceived danger } & 1 & .829 & .049 & .053 & .090 & -.001 & .048 & .109 \\
\hline & 2 & .816 & -.044 & .064 & -.023 & .012 & -.031 & .109 \\
\hline & 3 & .815 & .005 & .102 & .073 & -.064 & .046 & .011 \\
\hline & 4 & .806 & -.059 & .056 & -.103 & .032 & .034 & .083 \\
\hline & 5 & .803 & .018 & -.015 & -.155 & .091 & .062 & .043 \\
\hline & 6 & .779 & -.075 & .092 & -.021 & .128 & .038 & -.038 \\
\hline & 7 & .774 & -.036 & .109 & -.164 & .066 & -.025 & .070 \\
\hline & 8 & .750 & -.019 & -.062 & -.027 & .157 & .050 & .096 \\
\hline \multirow{7}{*}{ Emotionality } & 1 & -.064 & .807 & .125 & .265 & .232 & -.014 & .106 \\
\hline & 2 & -.038 & .805 & .194 & .202 & .229 & .160 & .085 \\
\hline & 3 & -.016 & .776 & .250 & .193 & .182 & .044 & .099 \\
\hline & 4 & -.041 & .751 & .154 & .294 & .183 & .133 & .039 \\
\hline & 5 & -.001 & .731 & .097 & .348 & .076 & -.006 & .144 \\
\hline & 6 & .003 & .716 & .236 & .299 & .027 & .163 & .058 \\
\hline & 7 & -.042 & .677 & .239 & .298 & -.011 & .241 & .095 \\
\hline \multirow{8}{*}{ Informativity } & 1 & .152 & .198 & .768 & .204 & -.018 & .121 & .036 \\
\hline & 2 & .117 & .230 & .763 & .217 & -.034 & .084 & -.027 \\
\hline & 3 & .033 & .115 & .736 & .135 & .163 & .060 & .164 \\
\hline & 4 & .019 & .142 & .732 & .089 & .187 & .078 & .140 \\
\hline & 5 & .023 & .256 & .726 & .153 & .188 & .137 & .034 \\
\hline & 6 & -.017 & .161 & .707 & .046 & .329 & .009 & .217 \\
\hline & 7 & .070 & .136 & .699 & .097 & .209 & -.057 & .194 \\
\hline & 8 & .095 & .001 & .642 & .092 & .296 & .031 & .253 \\
\hline \multirow{6}{*}{ Personalization } & 1 & -.133 & .383 & .157 & .764 & .101 & .099 & .066 \\
\hline & 2 & -.073 & .320 & .241 & .761 & .043 & .122 & .099 \\
\hline & 3 & -.053 & .373 & .181 & .734 & .084 & .160 & .006 \\
\hline & 4 & -.058 & .431 & .132 & .727 & .141 & .068 & .183 \\
\hline & 5 & -.079 & .318 & .164 & .719 & .214 & .167 & .008 \\
\hline & 6 & -.078 & .316 & .254 & .704 & .143 & .176 & .146 \\
\hline \multirow{4}{*}{ Functional } & 1 & .109 & .166 & .267 & .163 & .801 & .135 & .109 \\
\hline & 2 & .060 & .204 & .228 & .132 & .795 & .132 & .094 \\
\hline & 3 & .157 & .220 & .319 & .147 & .759 & .077 & .080 \\
\hline & 4 & .173 & .189 & .275 & .100 & .704 & .085 & .177 \\
\hline \multirow{4}{*}{ Customer attitudes } & 1 & .050 & .097 & .066 & .118 & .094 & .829 & .098 \\
\hline & 2 & .026 & .118 & .058 & .057 & .109 & .827 & .198 \\
\hline & 3 & .117 & .203 & .030 & .223 & .113 & .759 & .159 \\
\hline & 4 & .009 & .045 & .114 & .106 & .030 & .703 & .166 \\
\hline \multirow{4}{*}{ Purchasing intention } & 1 & .109 & .098 & .231 & .009 & .129 & .178 & .800 \\
\hline & 2 & .136 & .229 & .159 & .028 & .095 & .121 & .747 \\
\hline & 3 & .169 & .086 & .204 & .156 & .161 & .258 & .707 \\
\hline & 4 & .119 & .063 & .217 & .226 & .058 & .299 & .611 \\
\hline \multicolumn{2}{|l|}{ Eigen value } & 5.345 & 5.291 & 5.201 & 4.242 & 3.116 & 3.005 & 2.609 \\
\hline \multicolumn{2}{|l|}{ Disersion ratio } & 13.037 & 12.906 & 12.685 & 10.345 & 7.601 & 7.330 & 6.363 \\
\hline
\end{tabular}




\subsection{Hyphthesis Verification Results}

신뢰성과 타당성 분석이 진행된 후, 가설 검증은 구조방정식모형을 통하여 분석되었다. 분석 결과, 유의도 $(\mathrm{p}<0.05)$ 수준에서 가설 1 과 가설 3 은 기각되었으나, 그 이외의 가설 2, 가설 4, 가설 5, 가설 6 은 모두 유의하게 지지가 되었다. 즉, 옵트인 메일의 기능성, 개인화는 고객태도에 긍정적 영향을 미치는 지각된 위험은 고객 태도에 부정적 영향을 미치는 것으로 나타났다. 또한, 고객 태도가 구매의도에 긍정적 미치는 긍정적 영향도 확인되었다.

Table 4: Hypothesis Verification Results

\begin{tabular}{|c|c|c|c|c|c|}
\hline $\begin{array}{c}\text { Dependent } \\
\text { Variable }\end{array}$ & $\begin{array}{c}\text { Independent } \\
\text { Variable }\end{array}$ & $\begin{array}{c}\text { Path Coefficient } \\
\text { (Standardization) }\end{array}$ & S.E. & CR & P \\
\hline \multirow{2}{*}{$\begin{array}{c}\text { Customer } \\
\text { attitudes }\end{array}$} & Informativity & 0.001 & 0.059 & 0.008 & 0.993 \\
\cline { 2 - 6 } & Functional & 0.165 & 0.057 & 2.012 & $0.044^{* *}$ \\
\cline { 2 - 6 } & Emotionality & 0.065 & 0.060 & 0.636 & 0.525 \\
\cline { 2 - 6 } & Personalization & 0.326 & 0.060 & 3.270 & $0.001^{* *}$ \\
\cline { 2 - 6 } & $\begin{array}{c}\text { Perceived } \\
\text { danger }\end{array}$ & 0.154 & 0.042 & 2.472 & $0.013^{* *}$ \\
\hline $\begin{array}{c}\text { Purchasing } \\
\text { intention }\end{array}$ & $\begin{array}{c}\text { Customer } \\
\text { attitudes }\end{array}$ & 0.581 & 0.102 & 7.356 & $0.000^{* *}$ \\
\hline
\end{tabular}

\section{Conclusions}

\subsection{Research Results}

본 연구 결과는 개인정보를 활용한 마케팅 활용이 증대하는 상황에서, 소비자의 프라이버시 등 부정적 효과의 위험성을 인식하고, 기업과 소비자 모두에게 긍정적 효과를 높일 수 있는 방향에 관하여 실증적 연구를 진행하였다는 점에서 의의가 있다. 본 연구의 결과를 바탕으로 시사점을 제시하면 다음과 같다.

첫째, 기능성이 옵트인 메일 태도에 미치는 영향은 유의하게 입증되었다. 비록 메일의 수신이 번거롭게 여겨질 수 있지만, 이를 통하여 충분히 유용한 정보를 획득하거나 소비자 개인의 이익이 증대될 수 있다고 지각된다면 긍정적 고객 태도를 기대할 수 있다. 이는 마케터가 고객과의 상호작용 증대를 위하여 형식적, 반복적으로 이메일을 보내기보다는, 이메일 자체를 하나의 정보 및 광고의 미디어로 인식하고, 소비자 입장에서 가치 있는 내용이나 정보를 담아 전송해야 하는 것을 의미한다.

둘째, 개인화가 옵트인 메일 태도에 미치는 영향도 유의하게 입증되었다. 개인화된 이메일은 소비자에게 적합한 정보와 내용만으로 구성되어 있으므로, 소비자들은 이메일에 대한 반응을 보이거나 이를
열람하기 위한 시간과 노력의 투입을 정당하게 여길 것이다. 반면에 매스 마케팅의 일환으로 전개된 이메일은 불필요한 정보로 구성된 스팸메일로 처리될 것이다.

셋째, 지각된 위험이 옵트인 메일 태도에 대하여 부정적 영향을 미침이 확인되었다. 개인화된 데이터베이스의 다양한 혜택에도 불구하고, 소비자들에게 개인정보의 제공은 심각한 프라이버시에 대한 우려를 제공한다. 따라서 개인이 많은 정보를 제공하더라도 프라이버시는 지켜질 것이라는 신뢰와 확신이 필요하다. 이를 위하여 더욱 객관적이고 엄정한 고객 정보의 관리 절차 수립, 운영상의 정보 유출 가능성의 차단, 정보 유출 시 고객 보상 및 복구에 대한 의지 표현 등 기업의 성의 있는 자세와 책임감이 요구된다.

넷째, 옵트인 메일에 대한 태도는 구매의도에 직접적 영향을 미침으로써, 이메일이 여전히 마케팅 성과에 도움이 되는 수단임을 확인하였다.

그러나 정보성이나 정서성이 옵트인 메일 태도에 미치는 긍정적인 영향력은 확인되지 않았다. 우선 정보성이 기각된 것은 소비자들이 이메일 수신 동의에 따른 인센티브나 추가적인 정보 제공의 기회를 잘 인지하지 못할 가능성을 제기한다. 실제로 고객 정보 제공에 따라 다양한 혜택이 있다고 기업들은 주장하나, 그 혜택이 고객의 기대 수준에 미치지 못할 정도로 보상이 적거나, 로열티 프로그램, 마일리지 제도 등 다른 경쟁적인 마케팅 수단보다 차별화 정도가 낮을 수 있다. 또한, 정서성의 영향력도 기각되었다. 이는 이메일을 통하여 감동적인 스토리나 정서적인 콘텐츠를 제공하려는 기업들의 노력에도 불구하고, 이런 정서적 메시지 전달에는 적합한 매체가 아닐 수 있음을 의미한다.

\subsection{Implications}

본 연구는 그동안 학술적으로나 실무적으로나 그저 고객의 동의를 구한 뒤 전개하는 마케팅의 일부로써 인식되어 결국은 고객의 동의를 구하는 점만 제외하면 여타 마케팅 방법론과 차이 없이 적용되어 왔던 옵트인 마케팅을 기존 웹.메일 광고 선행요인에 적용하여 실증 규명하였다는 점에서 학술적인 시사점이 있다고 할 수 있다. 또한 그동안 옵트인 광고에서는 연구된 바가 없는 부정적인 영향을 주는 요인에 대한 고려를 하였다는 점에서 이를 시작으로 옵트인 광고에 대한 연구 방향에 다소간 균형을 이룰 수 있는 여지를 마련하였다고 할 수 있다. 더욱이 기존 실무적 차원에서의 활발한 논의와는 다르게 학술적으로는 IT 기술의 발달에 따른 개인정보 유출에 대한 소비자 개개인 또는 사회적 우려와 관련된 현실적인 측면을 뒷받침할 수 있을 만한 연구가 충분치 않았다. 기존 개별적인 프라이버시에 관한 연구에서는 개인적 차원의 프라이버시를 고려하기보다는 제도적 장치에 기반한 신뢰성 즉, 조직적 차원에서의 신뢰성을 확충하는 것이 더욱 중요하다는 결론들이 지배적이었다. 이러한 선행연구의 방향성에 
더해 본 연구는 옵트인 마케팅이 개인정보에 대한 제공 동의가 선행되는 마케팅으로써 개인적 차원의 프라이버시에 대한 고려가 선행되어야 진정 긍정적인 고객태도를 형성할 수 있음을 시사하고 있다. 특히 본 연구는 옵트인이 적용된 이메일 광고를 중심으로 연구가 진행되고 있는 바에 따라 이메일 광고태도에 영향을 미치는 선행요인에 대한 변화상을 보여준다고 할 수 있다. 본 연구가 진행된 시점을 기준으로 이메일 광고는 사실상 대부분의 광고가 옵트인 메일 광고에 해당한다고 볼 수 있다. 이는 제도적인 장치로 개인정보보호법 제 22 조 제 3 항과 정보통신망법 제 50 조 제 1 항이 존재하기 때문이다. 본 연구는 이러한 시대적, 제도적 변화상이 반영된 결과라고 할 수 있을 것이며, 이에 따라 기존 연구에서는 유의미한 영향력을 보여주었던 요인인 정보성과 정서성이 현시점에서의 유의성이 존재하지 않는 요인으로 변화하였다는 것을 실증하였다는 점에서 이론적으로 시사하는 바가 있다고 할 수 있을 것이다.

또한 본 연구는 기업의 마케팅 담당자들의 실무에 있어서도 기여하는 바가 있다고 할 수 있는데, 첫 번째로는 현시점에서의 이메일 광고는 옵트인 규약 또는 제도에 의해 제도적 안전장치가 마련되어 있어 이를 지키며 이메일 광고를 단행한다고 하더라도 고객의 입장에서 그 위험성에 대한 지각 수준을 살펴보아야 할 것이다. 이에 기업에서는 데이터베이스를 활용한 개인화 마케팅의 수준과 소비자들의 위험에 대한 지각 수준의 임계점을 넘치지 않는 수준에서 적절히 고려하여 마케팅을 전개할 필요가 있다. 고객정보를 활용한 마케팅 활동은 법적 테두리 안에서 이루어져야 함은 당연하고 개인정보 활용 수준을 최소화함과 동시에 적정 수준의 개인맞춤형 광고를 제공해줄 수 있어야 할 것이다.

두 번째로는 기존 이메일 광고와는 그 접근 방식을 달리해야 한다는 점이다. 기존 웹 광고 혹은 이메일 광고에 관한 연구에서는 광고의 정보성, 기능성, 정서성, 개인화 등이 긍정적인 영향력을 발휘하는 것으로 밝혀졌다(Ducoffe, 1996). 그러나 시대가 변화하여 정보를 얻을 수 있는 채널과 소비자들의 정서적 상호작용 욕구를 해소할 수 있는 채널이 확대되며 소비자들은 더 이메일 광고에 정보제공 역할과 정서적 역할에 대한 요구를 하지 않게 되었다. 현시점에서의 이메일 광고는 고객이 지각하는 개인화 수준과 기능성 수준을 제고할 수 있는 방향으로 소비자 맞춤형으로 전개되어야 하며 담겨야 할 메시지에는 메일을 발신하는 기업 혹은 웹사이트에서 활용할 수 있는 인센티브나 실질적인 혜택이 담겨야 한다는 것이다.

마지막으로 이메일 광고에 대한 고객태도는 그 형태가 옵트인 규약 또는 제도적 장치에 의해 변화되었어도 구매의도에 유의미한 영향을 미치는 것으로 확인된 만큼 콘텐츠 차원에서 구매까지 이어질 수 있는 고객 여정을 고려할 필요가 있음을 시사한다. 뉴미디어가 탄생하고 매체의 다양성이 높아짐에도 불구하고 소비자들이 이메일 광고를 통해 여전히 기능성과 개인화에 대한 욕구를 충족하고 이를 토대로
고객태도를 형성함을 살펴보았다. 본 연구는 결론적으로 기업들의 통합된 마케팅 추진에 있어서 옵트인 메일 광고가 어떠한 역할을 할 수 있을 것인지에 대해 시사하는 바가 있다고 할 수 있다.

\subsection{Limits and Future Direction of Research}

이상의 연구 결과 및 실무적 시사점들에도 불구하고 본 연구는 한계가 존재한다. 우선 옵트인 메일에 대한 선행요인들이 선행연구를 통해 도출된 항목이지만 일정 수준 연구자의 주관적 판단이 개입되었기 때문에 이론적 타당성이 다소 부족할 수 있다는 점이다. Herzberg et al.(1959)의 2 요인 이론을 프레임워크로 적용하여 긍정적 요인 차원과 부정적 요인 차원을 구성하였지만 최근 이메일 광고 분야에 한정하여 개인정보 보호와 관련한 지각된 위험을 부정적인 요인으로 구성하였을 뿐 개인화를 제외한 정보성, 기능성, 정서성에 대칭되는 부정적 요인에 대한 구성은 미흡하였다고 할 수 있다.

또한 현시점에서의 이메일 광고 이용행태에 대한 고찰이 부족했다는 점을 한계점으로 꼽을 수 있을 것이다. 어떠한 커뮤니케이션 채널이든 그 특유의 속성을 갖는다는 점을 생각해 본다면 본 연구에서도 이메일 광고 태도에 영향을 주는 개인 편차 혹은 이메일 광고 이용행태와 관련된 변수들을 통제변수 또는 조절변수로 적용할 필요성이 존재하게 된다. 이와 같이 이메일 광고 수신자 개인이 갖는 특성과 이들의 이용행태에 대한 연구가 본 연구와 같이 이루어졌다면 세부적인 결론에 도달할 수 있었을 수도 있었을 것이라는 한계점이 존재한다.

마지막으로 본 연구는 설문조사에 기인한 한계점을 지닌다. 시간 및 인력의 제약으로 인해 실험적 연구가 아닌 설문조사 형태의 연구가 추진되었기에 응답자의 기억에 의존할 수밖에 없다는 한계점이 있다. 연령 및 이용행태 등에 있어서는 적절한 조사가 이루어졌다고 할 수 있으나, 지역적으로는 중부권에 국한된 조사가 이루어져 대한민국 전역에 걸친 일반화는 다소 어려울 수 있다. 또한 조사대상이 그 당시 상황과 인식 수준을 명확하게 기억하기 어려우며 시간 경과의 편차에 따라 기억이 왜곡될 수 있다는 가능성이 전제되지 않았다. 자료수집 방법에서의 설문조사는 대부분 회상적 자기보고방식을 채택하지만, 이는 결국 자전적 기억(Autobiographical memory)에 의존하기에 조사대상자가 인간인 이상 경험을 정확하게 해석할 수 없기 때문에 한계점을 가진다고 할 수 있다(Bradburn, Rips, \& Shevell, 1987). 더불어 상기 전반에 걸친 제약에 따라 동일방법편의 문제가 제기될 수 있다. 동일방법편의의 제거를 위해서는 응답의 원천 또는 측정환경을 달리하거나 자료 수집 단계에서 설문항목 및 순서 등을 변화시키는 등의 방법이 적용될 수 있는데(Podsakoff, MacKenzie, \& Lee, 2003; Podsakoff \& Organ, 1986; Converse, 1986; Kahn \& Cannell, 1957), 향후 본 연구의 확장 또는 연계에서는 이러한 방안이 연구 설계 단계부터 강구되어 적용된다면 더욱 바람직한 
결과물을 얻을 수 있을 것으로 판단된다.

\section{References}

Agarwal, R., \& Karahanna, E. (2000). Time flies when you're having fun: Cognitive absorption and beliefs about information technology usage. MIS Quarterly, 24(4), 665694.

Ahmad, A. E. M. K., \& Al-Zu'bi, H. A. (2011). E-banking functionality and outcomes of customer satisfaction: an empirical investigation. International Journal of Marketing Studies, 3(1), 50-65.

Bai, B., Law, R., \& Wen, I. (2008). The impact of website quality on customer satisfaction and purchase intentions: Evidence from Chinese online visitors. International Journal of Hospitality Management, 27(3), 391-402.

Bauer, H. H., Hammerschmidt, M., \& Falk, T. (2005). Measuring the quality of e-banking portals. International Journal of Bank Marketing, 23(2), 153-175.

Bellman, S., Johnson, E. J., \& Lohse, G. L. (2001). On site: To opt-in or opt-out? It depends on the question. Communications of the ACM, 44(2), 25-27.

Bradburn, N. M., Rips, L. J., \& Shevell, S. K. (1987). Answering autobiographical questions: The impact of memory and inference on surveys. Science, 236(4798), 157-161.

Bredahl, L. (2001). Determinants of consumer attitudes and purchase intentions with regard to genetically modified foodresults of a cross-national survey. Journal of Consumer Policy, 24(1), 23-61.

Brown, S. P., \& Stayman, D. M. (1992). Antecedent and consequences of attitude toward the Ad: A meta-analysis. Journal of Consumer Research, 19(1), 34-5.

Bahn, K. D., \& Wright, N. D. (2001), Antecedents of green product purchase behavior. The Academy of Marketing Studies, 6(2), 51-55.

Carmines, E. G., \& Zeller, R. A. (1979). Reliability and Validity Assessment. New York, USA: Sage Publications.

Chitturi, R., Raghunathan, R., \& Mahajan, V. (2007). Form versus function: How the intensities of specific emotions evoked in functional versus hedonic trade-offs mediate product preferences. Journal of Marketing Research, 44(4), 702-714.

Converse, J. M., \& Presser, S. (1986). Survey questions: Handcrafting the standardized questionnaire. New York, USA: Sage.

Campbell, D. E., \& Wright, R. T. (2008). Shut-up I don't care: Understanding the role of relevance and interactivity on customer attitudes toward repetitive online advertising. Journal of Electronic Commerce Research, 9(1), 62-76.

Chaudhuri, A., \& Holbrook, M. B. (2001). The chain of effects from brand trust and brand affect to brand performance: the role of brand loyalty. Journal of Marketing, 65(2), 81-93.

Duffett, R. G. (2015). The influence of Facebook advertising on cognitive attitudes amid Generation Y. Electronic Commerce Research, 15(2), 243-267.

Davis, F. D. (1989). Perceived usefulness, perceived ease of use, and user acceptance of information technology. MIS Quarterly, 13(3), 319-340.
Davis, J. F. (1997). Property rights to consumer information: A proposed policy framework for direct marketing. Journal of Direct Marketing, 11(3), 32-43.

Ducoffe, R. H. (1996). Advertising value and advertising on the web-blog@management. Journal of Advertising Research, 36(5), 21-32.

DuFrene, D. D., Engelland, B. T., Lehman, C. M., \& Pearson, R. A. (2005). Changes in consumer attitudes resulting from participation in a permission e-mail campaign. Journal of Current Issues \& Research in Advertising, 27(1), 65-77.

Dwyer, F. R., Schurr, P. H., \& Oh, S. (1987). Developing buyerseller relationships. Journal of Marketing, 51(2), 11-27.

Fan, Q. J., Kim, W. K., \& Cui, G. (2010). Influence of marketing mix on customers attitude and purchase intention-mediating effects of customer experiences. The Journal of the Korea Contents Association, 10(8), 292-300.

Foxman, E. R., \& Kilcoyne, P. (1993). Information technology, marketing practice, and consumer privacy: Ethical issues. Journal of Public Policy \& Marketing, 12(1), 106-119.

Godin, S. (1999). Permission marketing: Turning strangers into friends and friends into customers. New York, USA: Simon and Schuster.

Gorla, N. (2012). Information systems service quality, zone of tolerance, and user satisfaction. Journal of Organizational and End User Computing(JOEUC), 24(2), 50-73.

Gefen, D. (2002). Customer Loyalty in E-Commerce. Journal of the Association for Information Systems, 3(0), 27-51.

Herzberg, F., \& Mausner, B. Snyderman. (1959). The motivation to work. New York, USA: Villey.

Hoffman, D. L., Novak, T. P., \& Peralta, M. A. (1999). Information privacy in the marketspace: Implications for the commercial uses of anonymity on the web. The Information Society, 15(2), 129-139.

Holbrook, M. B., \& Batra, R. (1987). Assessing the role of emotions as mediators of consumer responses to advertising. Journal of Consumer Research, 14(3), 404-420.

Jang, Y. S., Baek, S. W., \& Kim, S. H. (2018). The effects of brand equity on consumer attitude and behavior: Food market in vietnam. Journal of Distribution Science, 16(1), 17-27.

Jarvenpaa, S. L., Tractinsky, N., \& Vitale, M. (2000). Consumer trust in an internet store information technology and management. Journal of Information Systems, 12(1), 41-48.

Jacoby, J., \& Kaplan, L. (1972). The component of perceived risk. Proceedings 3rd Annual Conference of the Association for Consumer Research, 3(3), 382-393.

Kahn, R., \& Cannell, C. (1957). The dynamics of interviewing, New York, USA: Wiley.

Kim, H. S., Choi, Y. S., \& Shin, C. S. (2019). Relationship among restaurant owner's SNS marketing, trust, purchase intention, and word of mouth intention. Journal of Distribution Science, 17(7), 27-38.

Kim, M. J. \& Park, C. J. (2019). Does customer delight matter in the customer satisfaction-loyalty linkage?. Journal of Asian Finance, Economics and Business, 6(3), 235-245.

Li, W., \& Huang, Z. (2016). The research of influence factors of online behavioral advertising avoidance. American Journal of Industrial and Business Management, 6(9), 947.

Lewis, I. M., Watson, B., \& White, K. M. (2010). Response efficacy: The key to minimizing rejection and maximizing 
acceptance of emotion-based anti-speeding messages. Accident Analysis \& Prevention, 42(2), 459-467.

Malhotra, N. K., Kim, S. S., \& Agarwal, J. (2004). Internet users' information privacy concerns (IUIPC): The construct, the scale, and a causal model. Information Systems Research, 15(4), 336-355.

Milne, G. R., \& Rohm, A. J. (2000). Consumer privacy and name removal across direct marketing channels: Exploring opt-in and opt-out alternatives. Journal of Public Policy \& Marketing, 19(2), 238-249.

MacKenzie, S. B., Lutz, R. J., \& Belch, G. E. (1986). The role of attitude toward the ad as a mediator of advertising effectiveness: A test of competing explanations. Journal of marketing research, 23(2), 130-143.

Mitchell, A. A., \& Olson, J. C. (1981). Are product attribute beliefs the only mediator of advertising effects on brand attitude?. Journal of Marketing Research, 18(3), 318-332.

Norberg, P. A., Horne, D. R., \& Horne, D. A. (2007). The privacy paradox: Personal information disclosure intentions versus behaviors. Journal of Consumer Affairs, 41(1), 100-126.

Palmer, J. W., \& Griffith, D. A. (1998). An emerging model of Web site design for marketing. Communications of the ACM, 41(3), 44-51.

Personal Information Protection Commission. (2017). Personal information protection annual report. Seoul, Korea: PIPC (Personal Information Protection Commission) .

Personal Information Protection Commission. (2019). Personal information protection annual report. Seoul, Korea: PIPC (Personal Information Protection Commission) .

Podsakoff, P. M., \& Organ, D. W. (1986). Self-reports in organizational research: Problems and prospects. Journal of Management, 12(4), 531-544.

Podsakoff, P. M., MacKenzie, S. B., Lee, J. Y., \& Podsakoff, N. P. (2003). Common method biases in behavioral research: A critical review of the literature and recommended remedies. Journal of Applied Psychology, 88(5), 879.

Peter, J. P., \& Ryan, M. J. (1976). An investigation of perceived risk at the brand level. Journal of Marketing Research, 13(2), 184-188.

Ramkumar, G. (2007). Image recognition as a method for opt-in and applications for mobile marketing. International Journal of Mobile Marketing, 2(2), 42-49.

Smith, H. J., Milberg, S. J., \& Burke, S. J. (1996). Information privacy: Measuring individuals' concerns about organizational practices. MIS Quarterly, 20(0), 167-196.

Smith, Robert E. and William R. Swinyard. (1982). Information response models: An integrated approach. Journal of Marketing, 46(4), 81-93.

Swan, J. E., \& Combs, L. J. (1976). Product performance and consumer satisfaction: A new concept: An empirical study examines the influence of physical and psychological dimensions of product performance on consumer satisfaction. Journal of Marketing, 40(2), 25-33.

Szymanski, D. M., \& Hise, R. T. (2000). E-satisfaction: An initial examination. Journal of Retailing, 76(3), 309-322.

Stayman, D. M., \& Aaker, D.A. (1988). Are all effects of Adinduced feeling mediated by Ad?. Journal of Consumer Research, 15(3), 368-373.

Sinkovics, R. R., Pezderka, N., \& Haghirian, P. (2012). Determinants of consumer perceptions toward mobile advertising - a comparison between Japan and Austria. Journal of Interactive Marketing, 26(1), 21-32.

Tezinde, T., Smith, B., \& Murphy, J. (2002). Getting permission: Exploring factors affecting permission marketing, Journal of Interactive Marketing, 16(4), 28-36.

Tsang, M. M., Ho, S. C., \& Liang, T. P. (2004). Consumer attitudes toward mobile advertising: An empirical study. International Journal of Electronic Commerce, 8(3), 65-78.

Ur, B., Leon, P. G., Cranor, L. F., Shay, R., \& Wang, Y. (2012). Smart, useful, scary, creepy: Perceptions of online behavioral advertising. In Proceedings of the Eighth Symposium on Usable Privacy and Security, 4(0), 1-15.

Westin, A. F. (2003). Social and political dimensions of privacy. Journal of Social Issues, 59(2), 431-453. 